\title{
COMPARATIVE STUDY OF LENGTH AND DIAMETER OF UMBILICAL CORD IN NORMAL VS GESTATIONAL HYPERTENSIVE CASES IN A TERTIARY CARE HOSPITAL IN EASTERN NEPAL
}

Subodh Kumar Yadav, ${ }^{1}$ Renu Yadav, ${ }^{2}$ Abhishek Karn, ${ }^{3}$ Rakesh Kumar Adhikari ${ }^{1}$

\begin{abstract}
INTRODUCTION

The well being of the fetus and hence the baby is influenced by a number of factors among which the length and diameter of umbilical cord is one important aspect. Studies have found association between gestational hypertension and the structure of umbilical cord. The objective of this study was to determine the effects of gestational hypertension on the length and diameter of umbilical cord.
\end{abstract}

\section{MATERIAL AND METHODS}

A total of 70 umbilical cords with placenta were collected in Nobel Medical College and Teaching Hospital for comparison of umbilical cords length and diameter between normotensives and patients with gestational hypertension. Data were statistically analyzed.

\section{RESULTS}

The difference in umbilical cords' diameter was statistically significant between normotensives and patients with gestational hypertension whereas the length of the umbilical cord had no statistically significant difference.

\section{CONCLUSION}

We concluded that gestational hypertension affects the diameter of umbilical cord by decreasing it significantly which may affect normal fetal development.

KEYWORDS Diameter, Gestational hypertension, Length, Umbilical cord

1. Department of Human Anatomy, Nobel Medical College and Teaching Hospital, Biratnagar, Nepal.

2. Department of Human Physiology, Nobel Medical College and Teaching Hospital, Biratnagar, Nepal

3. Department of Forensic Medicine, Universal College of Medical Sciences, Bhairahawa, Nepal.

DOI: http//doi.org/10.3126/jucms.v7i2.27143

\author{
For Correspondence \\ Dr. Abhishek Karn \\ Department of Forensic Medicine \\ Universal College of Medical Sciences \& \\ Teaching Hospital \\ Bhairahawa, Nepal \\ Email:dr.abhishekkarn@gmail.com
}




\section{INTRODUCTION}

Umbilical cord also known as funis is a flexible cord like structure connecting a fetus at the navel with the placenta and containing two umbilical arteries and one umbilical vein that transport nourishment to the fetus and removes its wastes. ${ }^{1}$ It makes a stable connection to the fetomaternal interface and is the indispensable life-sustaining connection between fetus and placenta. ${ }^{2}$ Its length is approximately equal to the crownrump length of the fetus throughout pregnancy and in a full term baby it is about 50 centimeters long and 2 centimeters in diameter. ${ }^{3}$ The well being of the fetus is influenced by a number of factors among which the umbilical cord structure is one important aspect. ${ }^{4}$ Hypertension, one of the causes of maternal as well as fetal mortality and morbidity is found in 4$5 \%$ of pregnant females. ${ }^{5}$ Gestational hypertension or Pregnancy Induced Hypertension (PIH), being a frequent obstetrical state, increases the menace of mortality and morbidity in fetus with hypertensive mothers. ${ }^{5}$ Poor blood supply to the intervillous spaces of placenta is found in PIH which may lead to placental abruption and preterm birth and also to fetal hypoxia which results in low birth weight. ${ }^{6-8}$ The babies born out of gestational hypertensive cases are more likely to gain hypertension later on. ${ }^{9}$

PIH is defined as systolic blood pressure $>140 \mathrm{mmHg}$ and diastolic blood pressure $>90 \mathrm{mmHg}$ which complicates $6-10 \%$ of all pregnancies and is a major cause of fetal morbidity and mortality. ${ }^{10}$ It is considered to be severe when sustained elevations in systolic blood pressure $\geq 160 \mathrm{mmHg}$ and/or diastolic blood pressure $\geq 110 \mathrm{mmHg}$ are present. ${ }^{10}$ Fetuses of these mothers are at greater risk of intrauterine growth retardation, prematurity and intrauterine death. ${ }^{10}$ As the umbilical cord lacks any nerve supply, the rate of blood flow through it is completely dependent upon its structure. ${ }^{11} \mathrm{PIH}$ is connected with abnormalities in the umbilical cord in many ways which can be morphological, biochemical and functional. ${ }^{12}$ Decrease in thickness of umbilical cord in gestational hypertension has been observed in many studies. ${ }^{13,14}$ With the view to find any significant change done by gestational hyper tension on the length and diameter of umbilical cord, this present observational study was done in a tertiary care hospital in eastern Nepal.

\section{MATERIAL AND METHODS}

This was an observational comparative study where a total of 70 umbilical cords with placenta ( 35 from normal patients and 35 from patients with gestational hypertension) were collected from the department of obstetrics and gynecology in Nobel Medical College and Teaching Hospital from $15^{\text {th }}$ January 2017 to $15^{\text {th }}$ January 2018 . Informed consent was obtained from each patient and ethical clearance was obtained from the
Institutional Review Committee of Nobel Medical College and Teaching Hospital. The inclusion criteria were: - Pregnant females of age between 20 to 35 years, gestational age were being 37 to 42 weeks and deliveries by either vaginal route or caesarean section. The exclusion criteria were: - Pregnant females who experienced any of these complications during pregnancy: anemia, diabetes mellitus, hypothyroidism, abruption placentae, multiple pregnancies, jaundice and intra uterine death or still birth. ${ }^{15}$ Whatever number of cases with these inclusion criteria came during the stimulated study period, we included them in our research

The umbilical cord with placenta were collected after delivery and washed thoroughly under tap water and wiped up with dry cotton pad. They were then placed in $10 \%$ formalin filled plastic container and transported to the Department of Anatomy. The length of these collected umbilical cords was measured with the non-elastic measuring tape. An additional 5 $\mathrm{cm}$ was added to each length measured for stump length compensation. ${ }^{16}$ The umbilical cords were cut crosssectionally at their thickest region and the maximum diameter was measured with a metallic scale. A second maximum diameter was measured at right angles to the first measured. Finally the mean diameter of the umbilical cord was calculated from these two measurements. ${ }^{17}$ Data were collected and statistical analysis was done by t-test using the Statistical Package for the Social Sciences (SPSS) version 20 (SPSS Inc, Chicago, IL, IBM version). Significance was defined as $p<0.05$

\section{RESULTS}

Out of the entire 70 umbilical cords, 35 were collected from normal pregnancies and 35 from gestational hypertensive pregnancies. The mean length of umbilical cord from normal pregnancy was $45.24 \pm 3.77 \mathrm{~cm}$ and that in case of umbilical cord from gestational hypertensive pregnancy was $46.84 \pm$ $3.99 \mathrm{~cm}$. The mean diameter of umbilical cord from normal pregnancy was $1.21 \pm 0.30 \mathrm{~cm}$ and that in case of umbilical cord from gestational hypertensive pregnancy was $1.06 \pm 0.14$ $\mathrm{cm}$. When the observed length and diameter of umbilical cords were compared between normal pregnancies and gestational hypertensive cases (Table 1), it was found that the diameter showed significant statistical differences at $p<0.05$, whereas the length did not show significant difference.

Table 1. Parameters and their statistical evaluation results

\begin{tabular}{lllll}
\hline Parameter & Normal Pregnancy & $\begin{array}{l}\text { Gestational Hypertensive } \\
\text { pregnancy }\end{array}$ & t-value & P-value \\
\hline $\begin{array}{l}\text { Length of umbilical } \\
\text { cord (Mean } \pm \text { SD) }\end{array}$ & $45.24 \pm 3.77$ & $46.84 \pm 3.39$ & -1.86 & 0.665 \\
$\begin{array}{l}\text { Diameter of } \\
\text { umbilical cord } \\
\text { (Mean } \pm \text { SD) }\end{array}$ & $1.21 \pm 0.30$ & $1.06 \pm 0.14$ & 2.62 & $0.010^{*}$ \\
\hline
\end{tabular}

SD:- Standard Deviation; * Statistically significant at $P<0.05$. 


\section{DISCUSSION}

Abnormalities in length and diameter of umbilical cord were associated with maternal gestational hypertension according to a study done by Olaya et al. ${ }^{12}$ Measurements of umbilical cord and its components are vital means in the evaluation of fetal growth. ${ }^{18}$

Anjum et al stated that the normal length of the umbilical cord is between $40-60 \mathrm{cms} .{ }^{19}$ In our study the average length was between 39 to $59.5 \mathrm{cms}$ in normal pregnancies and 42 to 53 $\mathrm{cms}$ in gestational hypertensive pregnancies. Muhammad Yasoob et al found the mean of the length of umbilical cord in normal and gestational hypertensive cases to be $57.4 \mathrm{~cm}$ and $52.9 \mathrm{~cm}$ respectively. ${ }^{20}$ The average length of the umbilical cord was found to be $44.8 \pm 12.0$ and $44.3 \mathrm{~cm} \pm 9.2$ in normotensive and gestational hypertensive pregnancies respectively in a study by Peter Kwabena Appiah. ${ }^{21}$ A study by Goswami PR and Shah SN found the mean umbilical cord length to be $26.5 \mathrm{cms}$ in normal pregnancies and $22.5 \mathrm{cms}$ in gestational hypertensive pregnancies. ${ }^{22}$ In most of the studies the length showed some difference between normal and PIH cases, but was not statistically significant which was also observed in our study. The t-value was -1.86 and the $p$-value was 0.665 which was not significant statistically at $p<0.05$.

In most of the studies done, the diameter of umbilical cord was less in gestational hypertensive pregnancies; in some the difference was statistically significant whereas in others it was not. In a study done by Saha RR, Farhat N, Karmakar M the mean diameters of normal pregnancies and gestational hypertensive pregnanies was $1.16 \pm 0.36 \mathrm{~cm}$ and $1.04 \pm 0.17$ $\mathrm{cm}$ respectively. ${ }^{23}$ Bhavina K, Pandian SS, Priya G found the diameter of the umbilical cord on the foetal end to be $1.16 \pm$ $0.22 \mathrm{~cm}$ in gestational hypertensive cases. ${ }^{24}$ In a study done by Mah Paikar et al it was found that the mean diameter was 1.36 $\pm 0.39 \mathrm{cms}$ in normotensive group and $1.30 \pm 0.65 \mathrm{cms}$ in gestational hypertensive group. ${ }^{16}$ The reduction in diameter of the umbilical cord was statistically significant in groups with pregnancy induced hypertension as stated by Muhammad Yasoob et al. ${ }^{20}$ especially due to reduction in contents of Wharthon's jelly. Our study is in consistent with this finding where the mean diameter of umbilical cord from normal pregnancy was $1.21 \pm 0.30 \mathrm{~cm}$ and that in case of umbilical cord from gestational hypertensive pregnancy was $1.06 \pm 0.14$ $\mathrm{cm}$ and the difference was statistically significant. As stated by Tahmasebi $\mathrm{M}$ and Alighanbari $\mathrm{R}$, the reduction in the diameter of umbilical cord can compromise fetal growth. ${ }^{25}$

However, the limitation of our study was that we only studied gestational hypertensive cases coming to a tertiary care centre within one year. We recommend studying at multiple centres and for longer duration of time.

\section{CONCLUSION}

We concluded that gestational hypertension affects the diameter of umbilical cord in a major way by decreasing it significantly. Umbilical cord being the connection linking developing fetus and placenta, the changes in it may compromise the function of umbilical cord and adversely affect normal fetal development.

\section{REFERENCES}

1. Sadler TW. Fetal Membrane and Placenta. Langman's Embryology. 9th ed. Williams and Wilkins, Baltimore, 2003.

2. Bosselmann S, Mielke G. Sonographic Assessment of the Umbilical Cord. Geburtshilfe Frauenheilkd. 2015;75(8):808-18.

3. Meyer WW, Rumpelt HJ, Yao AC, Lind J. "Structure and closure mechanism of the human umbilical artery". Eur. J. Pediatr. 1978; 128 (4):247-59.

4. Baptiste- Roberts K, Salafia CM, Nicholson WK, Duggan A, Wang NY, Brancati FL. Maternal risk factor for abnormal placental growth. The National Collaborative Perinatal Project. BMC Pregnancy and Child Birth. 2008;8:44.

5. Jain L. Effect of pregnancy-induced \& chronic hypertension on pregnancy outcome.Journal of Perinatology.1997;17(6):425-27.

6. Kaauaaur.k ,Jouppila P, Kuikka J, Loutala H , Toivanen.J, Rekonen A. Inter Villous Blood Flow In Normal \& Complicated Late Pregnancy Measured By Means Of Inter villous 133XE Method. Acta Obstetrician et Gynaecological Scandinavica. 1980;59(1):7-10.

7. Resnik R. Intra Uterine Growth Restriction High- Risk Pregnancy Series: an expert view. American College of Obstetricians \& Gynaecologists. 2002;99(3):490-6.

8. Fawzia A, Habib FA. Prediction Of low Birth Weight Infants from Ultra Sound Measurement of Placental Diameter and Placental Thickness. Ann Saudi Med. 2002; 22(5-6):312-14.

9. Eriksson J, Forsen T, Tuomilehto J, Osmond C, Barker D. Fetal and childhood growth and hypertension in adult life. Hyper tension. 2000;36(5):790-4.

10. Kintiraki E, Papakatsika S, Kotronis G, Goulis DG, Kotsis V. Pregnancy-Induced hypertension. Hormones (Athens). 2015 Apr-Jun;14(2):211-23.

11. Fox SB, KhongTY. Lack of innervation of human umbilical cord. An immunohistological and histochemical study. Placenta. 1990;11(1)59-62.

12. Olaya CM, Salcedo Betancourt J, Galvis SH, Ortiz AM, Gutierrez S, Bernal JE. Umbilical cord and preeclampsia. J Neonatal Perinatal Med. 2016;9(1):49-57. 
13. Hutchinson E.S, Brownbill P, Jones N.W, et al Uteroplacentaal Haemodynamics in the Pathogenesis of Preeclampsia. Placenta. 2009;30:634-41.

14. Junek T, Baum O, Lauter H, Vetter K,Matejevic D, Graf R. Preeclampsia Associated Alterations of the Elastic fiber systems in umbilical cord vessels. Anat Embryol. 2000;201:291-303.

15. Agarwal GC, Saini P, Pankaj JP, Pandey LN, Jain A. Morphological study of placenta in normal and hypertensive pregnancies. IAIM. 2015;2(5): 121-8.

16. Paiker M, Mishra GM, Anans P, Bhatnagar S. Morphometric analysis of umbilical cord in normal vs hypertensive pregnancies in population of Lucknow, Uttar pradesh, India. Int J Anat Res. 2016; 4(3):2618-21.

17. Datta AK. Essentials of human anatomy: thorax and abdomen. 6th ed. Calcutta: Current Books International. 2003;67-8.

18. Togni FA, Araujo Júnior E, Vasques FA, Moron AF, Torloni MR, Nardozza LM. The cross-sectional area of umbilical cord components in normal pregnancy. Int $\mathrm{J}$ Gynaecol Obstet. 2007;96(3):156-61.

19. Anjum A, D. Suseelamma.S, Aritha, T.V.Ramani, D.Nagajyothi. Study of Morphologic Variation of 50 Placentae with Umbilical Cords and its Developmental relevance. International Journal of Anatomy and Research. 2015;3(3):1259-66.

20. Muhammad Y, Zahra HB, Bokhari MH, Tazeen N, Khalid A. Histomorphic Study of Umbilical Cord in Gestational Hypertension \& Preeclampsia. PJMHS. 2014;8(3):545-9.

21. Appiah PK. Relationship between The Morphology of Placenta, Umbilical Cord and Perinatal Outcome. M.Phil Thesis. 2009;5657.

22. Goswami PR, Shah SN. Placenta in Normal and Pregnancy Induced Hypertension in Relation to its Clinical Significance: A Gross Study. Int J Sci Stud. 2016;4(7):58-61.

23. Saha RR, Farhat N, Karmakar M. Study of Umbilical Cord in Pregnancy Induced Hypertension with and without Diabetes. Bangladesh Journal of Anatomy. 2014 January; 12(1):3-6.

24. Bhavina K, Pandian SS, Priya G. A Study on Morphology of Placenta and Umbilical Cord in Hypertensive Pregnancy with and without Proteinuria. International Journal of Biomedical Research. 2013;04(01):1-5.

25. Tahmasebi M, Alighanbari R. Evaluation of umbilical cord thickness, cross-sectional area, and coiling index as predictors of pregnancy outcome. Indian J Radiol Imaging. 2011;21(3): $195-8$. 